Invited Editorial

\title{
Samantha Adams Festschrift: Adamsian Discourse-The Patient, and Everything Else
}

\author{
Paul R. DeMuro ${ }^{1}$ Laurie L. Novak ${ }^{2}$ Carolyn Petersen ${ }^{3}$ \\ ${ }^{1}$ Broad and Cassel LLP, Fort Lauderdale, Florida, United States \\ ${ }^{2}$ Department of Biomedical Informatics, Vanderbilt University \\ Medical Center, Vanderbilt University, Nashville, Tennessee, \\ United States \\ ${ }^{3}$ Global Business Solutions, Mayo Clinic, Rochester, Minnesota, \\ United States
}

Appl Clin Inform 2018;9:500-502.

Samantha Ashley Adams, PhD, was a beloved teacher, PhD supervisor, and researcher. She represented the perspective of patients throughout her career. As early as 2002, Dr. Adams conducted research on reviewing and producing information reliability on the Web as part of her doctoral work. ${ }^{1}$ In one of the earlier works that she coauthored, she explored the use of "trust marks" which she defined as hyperlinked icons or seals that are placed on Web sites to denote review by an independent third party. ${ }^{2}$ She was concerned that many of the writings about trust marks at the time were critical of them. Dr. Adams noted many of these criticisms did not address the positive role of the review processes, and was concerned about how research in this area was not focused on the patient as the end user. She also was interested in the various approaches Web sites used to guide patients to health Web sites, recognizing that the process and pathway followed by patients could significantly influence their experience as well as their understanding of the information they received. ${ }^{3}$ Reliability of online health information was another key theme winding through her work. ${ }^{4}$

As part of her patient-focused work, Dr. Adams noted that informatics and published academic literature regarded patients as acting reflexively and proceeding with very specific information needs and views. ${ }^{5}$ However, she believed that individuals need help in developing skills for reflexive consumerism. Her work examined the role of the state and other political actors in the reliability of Web-based information within the context of existing relationships among technologies and users, nations and individuals, and individuals and their skill development. She noted that when patients describe their care experiences in online venues, the experience of writing about their care stimulates additional analysis of the health care process they and others have experienced. ${ }^{6}$ In addition, patients' reasons for sharing personal narratives may differ greatly from those of the organizations encouraging them to share these experiences, and that patients may be unaware of how organizations use patients' perceptions to frame conversations and shape other patients' expectations.

In 2008, Dr. Adams addressed blog-based applications and health information in the context of consumer health informatics. ${ }^{7}$ She was concerned that insufficient time was spent on applications available to the public and how blogs and other tools were being used. A pioneer in this area, Dr. Adams introduced the idea of health goal-oriented blogging. She considered how patients act as both information producers and information users within the blogosphere, and how these actions affect and are affected by health care-related organizations and policy makers. She noted that a lack of user experiences made it difficult to meaningfully assess health blogging from the patient's perspective.

Dr. Adams recognized the importance of qualitative research in health informatics, particularly in the evaluation of information technology and its impacts. ${ }^{8}$ She focused on disease management projects and chronic care in the context of technology and translated these notions from ones of global considerations of disease management to the local and individual patient level. In writing on the Dutch health system, she noted the work of disease management project leaders, suggesting that their work "not only guides the overall project, but impacts the interaction of one clinician with one patient, as well as traveling to the broader disease management arena through participation in research, through the development of care consortiums, and through the honing of standards and protocols within the Dutch health care system." ${ }^{9}$ She worked to describe the variability in development and implementation of disease management programs in the Netherlands, looking particularly at the wide variation in their development and implementation costs. ${ }^{10}$ In one study, she described eight cardiovascular disease
Address for correspondence Carolyn Petersen, MS, MBI, Global Business Solutions, Mayo Clinic, 200 First Street SW, Rochester, MN 55905, United States (e-mail: petersen.carolyn@mayo. edu).
(C) 2018 Georg Thieme Verlag KG Stuttgart · New York
DOI https://doi.org/ 10.1055/s-0038-1654701. ISSN 1869-0327. 
management programs as a way to find "insight into the forms of disease management and the feasibility of disease management approach."11 She found that disease management level, costs, health care utilization, patient characteristics, and health-related quality of life of patients varied wildly among the programs. Dr. Adams realized that activating patients was a key to patient-centered care and clinicians must act as collaborators. Her work in this area led to the study of patient reports of experiences with medications as a means of pharmacovigilance. ${ }^{12}$

Dr. Adams continued to recognize the important role of disease management programs in the health behavior of chronically ill patients by further noting the importance of the patient focus. ${ }^{13}$ She noted that patients needed support to make healthier lifestyle choices. It is important to listen to their needs and desires, and develop systems that improve communication among clinicians and between clinicians and patients who have chronic conditions. She also stressed the need to look for opportunities to motivate and support patients in the community. Her background in qualitative methods provided a basis for study of perceptions and use of online diaries for self-management of asthma and chronic obstructive pulmonary disease from the perspective of both patients and providers. ${ }^{14}$ The conclusion-that health care professionals should assist patients in using such diariesput patient needs front and center. This appreciation for the interaction between patients and providers applied to broader issues as well, for example, with regard to precision medicine as an organizing principle for patient care. She recognized that the ideas underlying precision medicine were not new, and that large-scale databases, new methods for categorizing and representing patients, and computational tools for analyzing large data sets create numerous opportunities, but also a possibility of loss of patient privacy, an increase in health inequity, greater challenges in ensuring informed consent, and a loss of focus on the patient. ${ }^{15}$

Although much of Dr. Adams' work addressed patientfacing issues directly, she also conducted research that highlighted the nuances of patient experience by focusing on other aspects of the health care system. She was interested in how patients and physicians interacted on Web sites designed to create patient-physician engagement, and noted that the presence of physicians could affect patients' perceptions of the information available in such communities. ${ }^{16}$ She also examined how regulators' expectations and experiences differed from those of the political system with regard to consumer/citizen involvement in review of health care institutions. $^{17}$

Dr. Adams' patient-focus recognized the importance of all relevant stakeholders in mobile health (mHealth).$^{18}$ In focusing on mHealth, she noted that although mHealth has a role in transforming health care, it is important to consider its context and the importance of primary stakeholders, which go well beyond patients to include families and caregivers, among others. Although patients remained a key focus, Dr. Adams recognized that they do not act in isolation from other groups in the health care system and considered interactions as well as individuals.
At the core of Dr. Adams's scholarship was the relationship between individuals (e.g., patients, citizens) and institutions (e.g., health systems, governments). She focused on how the everyday activities of individuals reproduce or change institutional structures that, in turn, enable and constrain individual activity. An example of this type of analysis is her treatment of the notion of "the clinic," in which she takes a novel perspective on the work of French historian and social theorist Michel Foucault, who explored the rise of the clinic (i.e., clinic or hospital) where individuals were redefined as "patients" and subjected to particular modes of assessment and analysis (the medical "gaze"). ${ }^{19}$ While other scholars have examined technology's contribution to the evolution of the gaze through new methods of medical surveillance, Dr. Adams focused on evolving notions of the clinic, given the availability of medical information on the Internet. ${ }^{20}$ If a person seeks medical information on the Internet, can they truly be defined as a patient? How do the traditional power relations and knowledge asymmetry between physicians and patients play out when telemedicine is used and the two are not interacting in the same space, with the patient vulnerable in a paper gown? She notes that the traditional brick and mortar "enclosure" of the clinic is being "distributed across apparatuses that may reveal, but also conceal, certain activities, data, and/or knowledge."20

Dr. Adams was particularly skilled at the juxtaposition of two sources of data, discourse and activity. One finds frequent references in her work to "discursive practices," a term that she uses to refer to several different phenomena. Discursive practices include the ways that people talk about phenomena in everyday life, formal communications from government or organizations, and social media activity from both individuals and institutions. Dr. Adams was able to use discourse analysis as a lens into the workings of the biocultural systems that we all participate in and examine how technology affects those workings.

Discourse analysis, particularly that which traverses multiple levels from everyday interactions among individuals to formal, institutional statements, can reveal subtle changes or inconsistencies in cultural patterns that are difficult to detect yet later seem apparent. An example is adaptations in language that reveal changes in scientific perspectives on what constitutes a disease-revealed ultimately in subsequent versions of the International Classification of Diseases. Dr. Adams produced a compelling analysis of discursive practices related to risk, a central topic in social analysis. Her focus was on the development of "eCoaches," a program that developed informatics solutions to help individuals implement "healthy" lifestyle changes. Her team analyzed documents and conducted focus groups and interviews with individuals to understand how the mobile applications became "imbued with certain norms and values, such as the moral imperative to be responsible for one's health."21 The analysis showed that the institutional documentation of the program framed stress, lack of sleep, and lack of exercise as "problems" that put the health system (and by extension, the society) at risk. At the individual level, participants discussed risks to the individual's privacy, proposing ways 
to "turn off" eCoach features that are too invasive. The analysis of risk discourses at multiple levels underlines the possibility that consumer health informatics tools developed to encourage adherence to healthy lifestyles may in fact "deepen existing social divides."

The implications of Adamsian discourse analysis for clinical informatics are several:

- We are compelled to clarify and document the meanings of new categories of data, their labels, and the trajectory of their existence. An example of special importance is the increasing use of geospatial data in health care analysis, with the potential of incorporating the information into electronic health records (EHRs) as "social determinants."

- We should document the social implications when we are presented with new taxonomies to be incorporated into clinical informatics design. For example, the inclusion of country of origin and travel history in the EHR, which supposedly imparts value for tracking potential exposures to severe acute respiratory syndrome and other diseases, may affect the way individuals are treated and whether they experience discrimination while obtaining care.

- The discipline should regularly reflect on the values that are being inscribed into technology that routinizes the work of millions of health care workers.

Dr. Adams' innovative and impactful work was in bloom at the time of her passing at a very young age. Her students and other professional colleagues are left to expand her work in an attempt to ensure better health care and health for all. She provided an excellent foundation for doing so.

\section{References}

1 Adams SA. Under construction: reviewing and producing information reliability on the web. (Werk in uitvoering over hetontwikkelen en beoordelen van informatiebetrouwabaarheid op het web.) Rotterdam, The Netherlands: Optima Grafische Communicatie; 2006

2 Adams SA, de Bont AA. More than just a mouse click: research into work practices behind the assignment of medical trust marks on the World Wide Web. Int J Med Inform 2007;76 Suppl 1): S14-S20

3 Adams SA, De Bont AA. Notions of reliability: considering the importance of difference in guiding patients to health care Web sites. Methods Inf Med 2003;42(04):307-312

4 Adams SA. Revisiting the online health information reliability debate in the wake of "web 2.0": an inter-disciplinary literature and website review. Int J Med Inform 2010;79(06):391-400
5 Adams S, de Bont A. Information Rx: prescribing good consumerism and responsible citizenship. Health Care Anal 2007;15(04): 273-290

6 Adams SA. Sourcing the crowd for health services improvement: the reflexive patient and "share-your-experience" websites. Soc Sci Med 2011;72(07):1069-1076

7 Adams SA. Blog-based applications and health information: two case studies that illustrate important questions for Consumer Health Informatics (CHI) research. Int J Med Inform 2010;79(06): e89-e96

8 Niazkhani Z, Pirnejad H, Aarts J, Adams S, Bal R. Reporting qualitative research in health informatics: REQ-HI recommendations. Stud Health Technol Inform 2011;169:877-881

9 Walters BH, Adams SA, Nieboer AP, Bal R. Disease management projects and the Chronic Care Model in action: baseline qualitative research. BMC Health Serv Res 2012;12:114

10 Tsiachristas A, Waters BH, Adams SA, Bal R, Mölken MP. Identifying and explaining the variability in development and implementation costs of disease management programs in the Netherlands. BMC Health Serv Res 2014;14:518

11 Cramm JM, Tsiachristas A, Walters BH, et al. The management of cardiovascular disease in the Netherlands: analysis of different programmes. Int J Integr Care 2013;13:e028

12 Adams SA. Using patient-reported experiences for pharmacovigilance? Stud Health Technol Inform 2013;194:63-68

13 Cramm JM, Adams SA, Walters BH, et al. The role of disease management programs in the health behavior of chronically ill patients. Patient Educ Couns 2014;95(01):137-142

14 van Kruijssen V, van Staa A, Dwarswaard J, In 't Veen JC, Mennema $B$, Adams SA. Use of online self-management diaries in asthma and COPD: a qualitative study of subjects' and professionals' perceptions and behaviors. Respir Care 2015;60(08):1146-1156

15 Adams SA, Petersen C. Precision medicine: opportunities, possibilities, and challenges for patients and providers. J Am Med Inform Assoc 2016;23(04):787-790

16 Vennik FD, Adams SA, Faber MJ, Putters K. Expert and experiential knowledge in the same place: patients' experiences with online communities connecting patients and health professionals. Patient Educ Couns 2014;95(02):265-270

17 Adams SA, van de Bovenkamp H, Robben P. Including citizens in institutional reviews: expectations and experiences from the Dutch Healthcare Inspectorate. Health Expect 2015;18(05):1463-1473

18 Petersen C, Adams SA, DeMuro PR. mHealth: don't forget all the stakeholders in the business case. Med 20 2015;4(02):e4

19 Foucault M. The Birth of the Clinic. Translated by A. Sheridan. London: Tavistock; 1973

20 Adams S. Ubiquitous Digital Devices and Health: Reflections on Foucault's Notion of the 'Clinic'. In Adams S, Purtova N, Leenes R, eds, Under Observation: The Interplay Between eHealth and Surveillance. Cham, Switzerland: Springer; 2017

21 Adams S, Niezen M. Digital 'solutions' to unhealthy lifestyle 'problems': the construction of social and personal risks in the development of eCoaches. Health Risk Soc 2016;17(7-8):530-546 